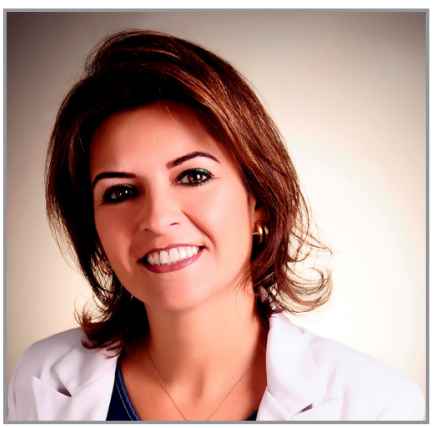

\title{
Women in Science: Current Status, Challenges, and Trends in Brazilian Analytical Chemistry
}

\author{
Márcia Foster Mesko \\ Associate Professor \\ Centro de Ciências Químicas, Farmacêuticas e de Alimentos \\ Universidade Federal de Pelotas - UFPel \\ Pelotas, RS, Brazil \\ marcia.mesko@pq.cnpq.br
}

The worldwide discussion regarding gender equity in science has grown in recent years. In Brazil, due to several recent actions, discussions about ensuring inequality reduction and the integration of minorities into society and diverse environments, including chemistry, have clearly increased.

In chemistry, as in many other areas of science in Brazil, few women hold prominent positions. However, the number of women who choose careers in the exact sciences and engineering, for example, is increasing, and this is probably related to various actions that stimulate and encourage women to choose such careers. Therefore, we must reflect on educational processes that begin in childhood, when girls are often discouraged from playing games or participating in activities simply because they are girls.

From my point of view, small changes to outdated habits can significantly influence the transformations we wish to promote. Nowadays, this is also evident in the scientific community, where the number of women who are active researchers and who occupy leadership positions is increasing. We must reflect on this and understand that gender differences promote diversity of thoughts, perceptions, and methods, which contributes significantly to the field.

In the scientific community, and in Brazilian chemistry specifically, more women are now prominent researchers, and this will certainly influence new generations of students. In particular, I believe that female chemists today play a key role in shaping the future of new scientists. We must, therefore, get rid of the preconceptions that still exist and, above all, continue to show that we are capable of pursuing any career we wish until everything happens naturally.

In my opinion, increasing initiatives and projects aimed at achieving gender equity in science remains fundamental to ensuring we have more opportunities to acquire leadership positions and pursue successful careers. We must think more about acknowledging the demands of women, who often care for their families and work twice as much as men to consolidate their careers. Moreover, in Brazil the difference between regional and racial issues must also be considered to correct historical misconceptions. In this context, actions that reduce public investment in education, science, and technology in our country are lamentable, as this leads to less social and economic development and decreases the chances of expanding opportunities for women working for scientific and technological development.

Various actions and programs have been proposed, and many of these are in evidence, such as maternity leave for scholarship researchers. In addition, gender diversity has been prioritized in the constitution of scientific committees, among other representative places. This will lead to new reflections that inform future actions. Unfortunately, the number of female analytical chemists in such places is still low. 
Furthermore, programs like "For Women in Science," promoted by L'Oréal, the Brazilian Academy of Sciences, and United Nations Educational, Scientific and Cultural Organization, recognize scientists throughout the country. Besides encouraging women to continue their research, the program also promotes the dissemination of each winner's scientific activities to society. Such actions draw attention to female scientists, bringing science closer to society and allowing more women to imagine themselves as scientists.

It is also important to mention the increasing number of female analytical chemists in Brazil. In this way, the Brazilian Chemical Society and its Analytical Chemistry Division have motivated discussions about this issue in recent years. Among such actions, the successful section dedicated to "Women in Analytical Chemistry: challenges and perspectives" during the $19^{\text {th }}$ National Meeting of Analytical Chemistry and the $7^{\text {th }}$ Ibero-American Congress of Analytical Chemistry is quite relevant. A surprising number of male and female participants discussed the current state of gender equity in the Brazilian analytical chemistry community. In my opinion, this type of action motivates and encourages young female researchers to continue their careers. I usually emphasize that gender equity is important to the sciences and society because male and female perceptions are complementary when observing the same phenomena.

Moreover, in my opinion, the sciences have grown significantly in Brazil in recent decades, and to achieve better results, government investments in education, science, and technology are essential. It is likewise important to mention that the number of female researchers in chemistry and analytical chemistry is growing and that public politics are essential to creating more opportunities for women. I hope to see gender equity achieved in the coming years.

Therefore, from my point of view reflections, discussions, and actions are essential for the promotion of necessary transformations in society and the sciences, especially regarding the inclusion of minorities. We must continue to show that gender diversity among professionals contributes to society and science in a meaningful way. Thus, in my opinion, it is still necessary to emphasize that it does not mean occupying the other's space, but that each has the right to occupy the space regardless of gender, race or skin color. 